\title{
The role of the dementia specialist nurse in acute care: a scoping review
}

Accepted for publication in the Journal of Clinical Nursing

Peter Griffiths PhD, BA(Hons), RN

Professor of Health Services Research, Faculty of Health Sciences, University of Southampton

Nightingale Building

Highfield Campus

Southampton SO17 1BJ

peter.griffiths@soton.ac.uk

Tel. +44(23) 80597877

*Jackie Bridges PhD, MSN, BNurs(Hons), RN, PG Cert

Senior Lecturer, Faculty of Health Sciences, University of Southampton

University of Southampton

Nightingale Building

Highfield Campus

Southampton SO17 1BJ

jackie.bridges@soton.ac.uk

+44(23) 80598282

Helen Sheldon MA, BA(Hons)

Freelance Research Consultant

42 The Chilterns, Gloucester Green, Oxford, OX1 2DF (NB Not for publication)

helensheldon@hotmail.com

Tel. +44(0)7970150 063

Rachel Thompson BA (Hons) RGN RMN PG Cert

Dementia Project Lead, Royal College of Nursing; Admiral Nurse, Dementia UK

Royal College of Nursing

20 Cavendish Square

London W1G ORN

rachel.thompson@rcn.org.uk

Tel. +44(0)20 76473727

*Corresponding author

This project was funded by the Royal College of Nursing and the RCN Foundation, but the findings presented are independent of influence from these organisations.

\section{Acknowledgements}

The authors would like to thank the following for their support and assistance as project advisers:

Dr Ruth Bartlett, University of Southampton

Tim Curry, Royal College of Nursing

Dr Katherine Hunt, University of Southampton

Nikki Mills, Royal College of Nursing

Michelle Parker, Barts Health NHS Trust 


\title{
The role of the dementia specialist nurse in acute care: a scoping review
}

\author{
ABSTRACT \\ Background: Extended stays and adverse events mean that hospital admissions are costly for people \\ with dementia, and patient experiences and outcomes can be poor. Specialist nurses have been \\ identified as having potential to enhance care quality, reduce excess stays and reduce costs, but the \\ evidence base for dementia specialist nurse roles has not previously been synthesised.
}

Aims and objectives: To identify the potential benefits of dementia specialist nursing and to inform the implementation of roles to support people with dementia during hospital admission.

Design: Scoping review.

Data sources: Cochrane Library, Campbell Collaboration, Clinical Evidence, Evidence-Based Medicine, York Centre for Reviews and Dissemination, PubMed, Medline, CINAHL, and Psyclnfo databases and internet searches and personal libraries / expert consultation to identify grey literature Methods: Initial scoping searches were used to inform more focused systematic searches. Studies directly evaluating dementia nurse specialist roles or giving evidence of effectiveness of interventions/services that could be delivered by them to improve core outcomes were identified by one reviewer and verified by a second reviewer.

Results: While direct evidence for the effectiveness of these roles is lacking, a number of areas were identified in which a nurse specialist role could make a contribution, including preventing adverse events and improving patient experiences and outcomes. There is a considerable body of evidence for the effectiveness of these interventions although the volume of evidence for specific interventions is not always significant.

Conclusions: The evidence indicates that a skilled dementia specialist nurse, undertaking a clearly defined role, and working directly with people with dementia and their carers for a significant proportion of the time, could benefit people with dementia in hospitals and their family carers. 
Relevance to practice: Clear guidance for the development and implementation of dementia specialist nurse roles in acute hospital settings.

\section{Key words}

Dementia

Alzheimer's

Nursing

Nurse specialist

Specialist nurse

Advanced practice

Hospitals

Acute care

What does this paper contribute to the wider global clinical community?

- This paper reports the identification and synthesis of the evidence base that can guide the development and implementation of dementia specialist nurse roles in acute hospital settings.

- It provides recommendations for an intervention that has the potential to improve the quality and safety of acute hospital care for people with dementia. 


\section{INTRODUCTION}

This paper presents the findings from a scoping review of the evidence base with the aim of informing the implementation of dementia specialist nurse roles in hospital settings. Dementia is an umbrella term for progressive disease processes (most commonly Alzheimer's disease) that cause cognitive impairment. It is a significant challenge and a key priority for health systems globally. Thirty-six million people globally were estimated to have dementia in 2010 , with this figure set to almost double to 66 million by 2030 (Alzheimer's Disease International 2013). People with dementia can be high users of health services. In the UK, for instance, it is estimated that at any one time up to $25 \%$ of acute hospital beds are occupied by people with dementia (Alzheimers Society 2009), with the figure likely to be considerably higher in some types of wards (Goldberg et al. 2012, Mukadam \& Sampson 2011). However, while there is increasing interest in dementia specialist nurse roles in the acute setting, the evidence base to support and guide the implementation of these roles has not been previously synthesized.

A focus on these roles in acute setting is worthwhile given the well documented issues regarding quality and outcomes of hospital care for people with dementia. People with dementia experience substantially longer hospital stays and require more nursing resources than similar patients without dementia (CHKS 2012, Mukadam \& Sampson 2011). They are more likely to experience adverse events including dehydration, falls and malnutrition, more likely to die or to be readmitted, and at high risk of losing their ability to care for themselves (CHKS 2012, Mukadam \& Sampson 2011, Sampson et al. 2012).

A conservative estimate of the additional costs to the English National Health Service (NHS) of these poor outcomes is over $£ 250,000,000$ per year, but this is likely to be a significant underestimate because dementia is often unrecognized or not recorded as a secondary diagnosis when people come into hospital (CHKS 2012). International evidence suggests that other health care systems produce similar outcomes for people with dementia (Wimo \& Prince 2010). 
In addition to the financial costs, the human costs are great. The experiences of care in hospitals for people with dementia are poor in the UK and these experiences are mirrored in health care systems internationally (Bridges et al. 2010). A UK survey conducted by the Alzheimer's Society found that a majority of family carers reported significant negative effects on the physical or mental health of the person with dementia that was unrelated to the medical condition that led to admission. Seventy seven percent were dissatisfied with the overall quality of dementia care in hospital (Alzheimers Society 2009). A national audit of dementia care in hospitals in England and Wales revealed significant shortcomings in both clinical and interpersonal care (Royal College of Psychiatrists 2011). While high quality person-centred care was found, this was only in 'pockets' with variation between wards and between individual caregivers in wards. A repeat audit identified some improvements but also identified significant scope for further improvement (Royal College of Psychiatrists 2013).

Part of the solution to this problem is to avoid unnecessary admissions (Alzheimers Society 2009, Crisp 2011) but this does not remove the challenge of providing high quality care for people with dementia in hospital. While many admissions are for conditions that could be treated in the community with early intervention or the provision of alternative services, many are not (Alzheimers Society 2009). People with dementia continue to have a right to acute care when the need arises. Their need for hospital care will continue to be significant as the population ages and the number of people with dementia rises (Crisp 2011).

The care delivered by nurses has been identified as being vital in supporting people with dementia and ensuring that the overall quality of hospital care is improved (Alzheimers Society 2009, Thompson \& Heath 2011). Many of the negative experiences and outcomes are directly or indirectly linked to nursing care (Griffiths et al. 2008, Maben et al. 2012) and, as part of a multidisciplinary team, nursing can contribute to improving these outcomes. Caring for people with dementia is difficult and complex but many nurses lack the specialist knowledge and skills required, and 
provision of education and training at all levels is, at best, variable (Alzheimers Society 2009, Royal College of Psychiatrists 2011, Skills for Health 2010).

In the UK, there is increasing interest in developing specialist nurse roles as part of the strategy to improve care of people with dementia. The competency framework developed for the "Admiral" specialist dementia nurses (Dewing \& Traynor 2005) provides a broad framework for understanding a dementia specialist nurse role:

- Therapeutic work (interventions)

- Sharing information about dementia and carer issues

- Advanced assessment skills

- Prioritizing work load

- Preventative and health promotion

- Ethical and person centred care

- Balancing the needs of the carer and the person with dementia

- Promoting best practice

Specialist nurses have a long history of providing excellent care for people with a variety of longterm conditions ${ }^{1}$. For example, specialist nurses in cancer care work to provide improved coordination, communication, and to give emotional support and supportive interventions for symptoms. Patients in NHS trusts with more cancer nurse specialists report better experiences of care on a range of dimensions (Griffiths et al. 2013c). Specialist nurses have been associated with economic benefits (Royal College of Nursing 2010) and work in a variety of ways to support care

\footnotetext{
${ }^{1}$ While clearly codified in some countries, in the UK and elsewhere, terminology on advanced practice nursing roles remains ill-defined and inconsistently used (Bryant-Lukosius et al. 2004). We use the term specialist nurse to encompass all nurses in advanced roles (e.g. clinical nurse specialists, nurse practitioners, and nurse consultants) with a defined specialty.
} 
including direct care, consulting with other staff and supporting education and practice development (Leary et al. 2008).

The success of specialist nurses in other fields suggests an opportunity to ascertain the extent to which dementia specialist nurses could support their nursing colleagues and others in delivering high quality and safe care in hospital settings. This evidence has not previously been synthesised.

\section{AIMS}

This scoping review aims to identify the potential benefits and to inform the implementation of dementia specialist nurse roles to support people with dementia during hospital admission. While there are specialist roles focusing on admission avoidance and facilitating primary/secondary care transitions, the focus of this review is solely on roles operating in acute hospitals in inpatient areas, emergency departments and/or operating theatres. Given the known under-diagnosis of people with dementia, the review also encompassed interventions targeted at people with signs and symptoms of dementia, but not necessarily with a formal diagnosis. This paper summarises the findings from a written report of the review (Griffiths et al. 2013a).

\section{METHODS}

We drew on the broad principles of scoping review to give an overview of the existing research base relevant to the topic (Arksey \& O'Malley 2005, Davis et al. 2009). Initially broad searches using simple terms (e.g. "dementia nurse specialist") and with no date limits were undertaken across Medline, CINAHL, the Cochrane Library, Google Scholar and Google in order to gain a rapid an overview of the amount and quality of the evidence, derive topics for further systematic investigation and present a body of literature against which the findings of the more formal searches could be validated. 
Following on from this general scoping review, more systematic searches were carried out to identify high quality evidence of effectiveness for a specific set of outcomes related to the potential impact of the dementia specialist nurse role in hospitals. Because the initial scoping searches revealed a dearth of direct evidence, these searches aimed to identify interventions of known or likely effectiveness that could be delivered by dementia specialist nurses. These searches focussed on falls, length of stay and readmissions, the three core cost drivers of excess cost for hospital stays in a recent analysis of hospital admissions for people with dementia (CHKS 2012).

In addition we searched for evidence and reviewed research literature in relation to other specific interventions and outcomes relevant to the dementia specialist nurse role, focusing on studies which provided evidence for the potential effectiveness of such a role, including:

- Screening, diagnosis and assessment

- Pressure ulcers

- Delirium

- Agitation and behavioural symptoms of dementia

- Behaviour, knowledge and attitudes of non-specialist staff (including nursing and medical staff)

- Patient and carer reported outcomes (quality of life and experiences of care)

These outcomes were selected as being potentially nurse sensitive based on recent overviews (Griffiths et al. 2008, Maben et al. 2012) and consultation with experts in the field. Searches of the Cochrane Library, Campbell Collaboration, Clinical Evidence, Evidence-Based Medicine, York Centre for Reviews and Dissemination, PubMed, Medline, CINAHL, and Psyclnfo databases were undertaken from December 2012 to March 2013 (see online appendix for more detail of the search strategies (Griffiths et al. 2013b)). A Project Advisory Group of academics with expertise in dementia care helped identify relevant grey literature. One reviewer selected evidence for inclusion with verification from a second reviewer. This included checking the relevance of all included material 
and assessing the accuracy of decisions to exclude material. Consistent with the scoping methodology we aimed to give an overview of the nature and extent of high quality evidence available. Where existing systematic review were found we used these as our primary source. Where they did not exist we sought material at the top of widely recognised hierarchies of evidence for effectiveness, only moving further down the hierarchy if no relevant material was found. A simple version of the hierarchy of evidence for studies of effectiveness is shown in Figure 1 . Where relevant, this paper also draws on material outside the immediate scope of the review in order to set findings in the context of the wider evidence base. For each outcome we also considered the implications of the evidence reviewed for the role of the dementia specialist nurse. Because the evidence is largely indirect, this analysis is mainly in terms of mechanisms by which a specialist nurse could influence outcomes, based on interventions of known or likely effectiveness. No formal synthesis was undertaken but a narrative description of findings is given, as appropriate for a scoping review.

\section{RESULTS}

A single empirical study reports on and evaluates the role of a dementia specialist nurse in an acute hospital setting (Elliot \& Adams 2011). Priorities included raising awareness of dementia among staff and providing good quality information for people with dementia and their family carers, improving inpatient care for patients with the condition and, where appropriate, facilitating optimum end-of-life care for them. The role is described as being based on a person-centred approach. Specific aspects of the role described include addressing behaviour that challenges and discouraging inappropriate sedation, facilitating dementia training for other staff based on a person centred approach, developing a dementia policy including pathways and screening tools for use by all hospital staff, detailed care planning including all the activities of daily living (Alzheimers Society 2009), consultation on dementia specific pain assessment, and screening for delirium and 
depression. A role in admission avoidance through providing consultation and assessment on patients in accident and emergency is also described.

The role was delivered by a single nurse in a 538 bed hospital who screened 20 new cases per month and provided on-going support to an average of 18 patients through daily follow-up in the hospital. The authors estimate that 720 bed days per year were potentially saved by the introduction of the dementia specialist nurse based on a reduction of average stay from 11 to 9 days, although the empirical basis of this claim is unclear. While the evidence from this single evaluation cannot be placed in a high position on the hierarchy of evidence (Figure 1) and is therefore considered weak in terms of its capacity to indicate effectiveness, it does indicate potential for patient benefit and cost savings.

The remainder of this paper reviews research literature in more detail in relation to specific interventions and outcomes relevant to the dementia specialist nurse role, focussing on studies which provide evidence for the potential effectiveness of such a role in a range of areas including prevention of falls and other adverse events, reducing length of stay and avoidable readmissions, contributing to screening and diagnosis of dementia, and staff education. Table 1 displays the search results used to inform the part of the review.

\section{Falls}

There is a substantial evidence base on falls prevention in hospitals, care homes and the community which is reported in a number of high quality systematic reviews (Cameron et al. 2012, Gillespie Lesley et al. 2012, Oliver et al. 2007, Udell et al. 2011). The evidence for simple single strategies for fall prevention in hospital (e.g. routine falls risk assessments) is weak (i.e. it is low on the hierarchy of evidence), whereas there is support for multifactorial interventions where an individual's risk is assessed and interventions targeted to their need. Evidence suggests that the rate of falls can be reduced by over $30 \%$ although evidence for a reduction of the risk of falling at all is less clear (Cameron et al. 2012). Effective interventions combine some or all of the following: exercise, 
medication review, management of urinary incontinence, fluid or nutritional therapy, environmental change or assistive technology and changes to the social environment.

Many of the studies in these systematic reviews explicitly exclude people with dementia and the evidence base for falls prevention in this group is much weaker. One systematic review found no overall association between dementia or cognitive impairment and the impact of strategies to prevent falls or fractures in care homes and hospital (Oliver et al. 2007), suggesting that the same broad approaches will work for people with dementia. Conversely a randomised controlled trial found that some otherwise effective strategies appear to be ineffective in people with cognitive impairment (Haines et al. 2011). Another study found that some effective strategies seem to most benefit those whose stays in hospital are longer (Haines et al. 2004).

Thus it seems likely that a reduction in falls among people with dementia in hospital is achievable. Prevention requires strategies that are tailored to the individual risk factors of the person with dementia. It is likely that some of these strategies will address risks that are directly related to dementia, such as wandering. Others will be based on fall prevention strategies known to be effective in the general older population but adapted for use with people with dementia.

A dementia specialist nurse could:

- Undertake individual risk assessments and plan / implement a tailored prevention strategy, based on best evidence

- Reduce risk by delivering support for specific dementia-related risk factors

- Advise on dementia-specific factors to be considered in broader strategies

\section{Length of stay}

Findings from a Cochrane systematic review indicate that nurse specialist roles in general can make a contribution to reducing length of hospital stay for hospitalised patients (Butler et al. 2011). The review included studies on the impact of masters-prepared specialist nursing roles focused on care 
coordination to address the needs of specific patient groups, such as patients with diabetes or multiple sclerosis. Results from a further systematic review that included studies on the impact of gerontological nurse practitioners, also suggest that such roles can help reduce length of stay (Newhouse et al. 2011). A number of primary studies indicate a clear contribution by specialist nurses to interdisciplinary interventions shown to be effective in reducing length of stay. These interventions include a clinical pathway for people with dementia (Kazui et al. 2004), a psychiatric and geriatric consultation service (Slaets et al. 1997) and an Acute Care for Elders (ACE) inpatient team (Benedict et al. 2006).

A dementia specialist nurse could:

- Provide comprehensive assessment and care coordination

- Oversee the delivery of inpatient care and progress review tailored to individual care needs and focused on reducing individual risk of adverse events

- Support other caregivers (including family carers) in identifying and delivering management strategies

- Support or undertake discharge planning as part of a multidisciplinary team

\section{Readmissions}

A number of studies provide evidence about the positive impact on readmission of interventions delivered by nurses, including nurse specialists, which have implications for the potential role of dementia specialist nurse. Most centre around ways of organising services for older people such as care management, liaison nurses, multidisciplinary approaches and discharge planning, although many studies have explicitly excluded older people with dementia and few report on them separately (Crotty et al. 2010, Ellis et al. 2011, Handoll et al. 2009, Handoll et al. 2011, Krichbaum 2007, Shepperd et al. 2010). Modest reductions in readmission were associated with discharge planning in a Cochrane systematic review (Shepperd et al. 2010) although the role of nurses in the interventions was not always clear and a systematic review of nurse staffing models found no 
evidence for a positive effect on readmissions from the addition of specialist nurses to the nursing team in general (Butler et al. 2011).

The advanced practice nurse transitional care model, in which experienced masters-prepared specialist nurses undertake discharge planning and coordinate care across the transition from hospital to home, has been extensively tested in the US with strong evidence from trials to support reduced readmissions and costs for some groups of older patients (Naylor et al. 2011). While outcomes have not yet been reported, this approach has been piloted and tested with cognitively impaired older adults (Bradway et al. 2012, Naylor et al. 2007, Naylor et al. 2005).

A dementia specialist nurse could:

- Provide comprehensive assessment and care coordination

- Support or undertake discharge planning as part of a multidisciplinary team

- Reduce readmissions by redesigning care delivery and implementing evidence based programmes

- Provide post-discharge follow-up and care coordination with community services

\section{Other adverse events}

People with dementia are vulnerable to other physical and psychological problems whilst in hospital including delirium, infection, pressure ulcers and post-operative respiratory complications. Evidence from a recent high quality randomised trial indicates that in general hospital settings, multiple risks (pressure ulcers, infection and falls) can be targeted through a multifaceted education and performance feedback programme (van Gaal et al. 2011). Inouye and colleagues found that a nursing education programme in a hospital setting resulted in a beneficial effect, preventing or reducing functional decline in frail older patients with delirium, functional impairment, incontinence, or pressure ulcers (Inouye et al. 1993). In a controlled before and after study, specialist 
gerontological nurses worked with staff in care homes to implement evidence based protocols leading to reductions in pressure ulcers, depression, and aggressive behaviour (Ryden et al. 2000).

While evidence for the effectiveness of non-pharmacological interventions for cognitive, behavioral, psychological and depressive symptoms of dementia is lacking (Butler \& Radhakrishnan 2011), there is a clear body of expert opinion relating to strategies for communicating with people with dementia (Cunningham \& McWilliam 2006, Tueth 1995, Zimmermann \& Ortigara 1998) aimed at avoidance of adverse events including in patients attending the emergency department (Clevenger et al. 2012). Similarly there are numerous aspects of environmental design that are likely to improve the experience of older people and reduce the risk of both physical and psychological adverse events (Mason 2011).

A dementia specialist nurse could:

- Support the dissemination and implementation of best practice in avoiding harm

- Enhance assessment and identify dementia specific risk factors and individual indicators of distress

- Give specific support, consultation and assessment in settings including A\&E and pre and post-operative units

- Review medication and ensure timely referral to liaison psychiatry services

\section{Screening and diagnosis}

There is a significant potential role for dementia specialist nurses in screening, assessment and diagnosis of dementia, but limited direct evidence of the impact. One systematic review addressed screening, diagnosis and assessment in A\&E but found no empirical studies. The use of standard cognitive screening by emergency nurses as a strategy for recognizing dementia in the Emergency Department is recommended (Andrews \& Christie 2009), as is assessment of delirium (Cunningham \& McWilliam 2006). One review identified a tool recommended for nurse administration (Hare et al. 
2008). A Geriatric Nursing Education Course has been shown to increase self-reported use of a cognitive assessment tool and an improvement in ability to screen for depression and dementia in a controlled before and after study (Brymer et al. 2001). There is evidence that appropriately trained specialist nurses can reliably identify and stage dementia using standardised instruments (McCulla et al. 1989, Page et al. 2008). Other more comprehensive interventions to support older people in hospital, such as the Hospitalised Elder Life Programme use specialist nurses to assess multiple risk factors, including cognitive impairment (Rubin et al. 2006, Steele 2010).

A dementia specialist nurse could:

- Support hospital wide strategies for case finding and screening

- Provide further detailed assessments for those identified by screening tests

- Initiate referrals for specialist diagnostic assessment

\section{Models of care}

People with dementia who are admitted to hospital are likely to have complex needs, which may be unrelated to the primary presenting condition, that need proper assessment and intervention to ensure optimal outcomes. These needs include nutrition, hydration and help with washing and dressing which are often unrecognised and unmet (Alzheimers Society 2009, Mukadam \& Sampson 2011). Disorientation and delirium are common (Mukadam \& Sampson 2011, Thomas et al. 2012), and often associated with agitation, distress, behaviours that staff find challenging and substantial morbidity (Thomas et al. 2012). In addition, the assessment and management of symptoms associated with the presenting condition, or other comorbidities, can become more complex because of cognitive impairment and communication difficulties. For example, pain can be difficult to assess and there is evidence that people with dementia may be given far less post-operative pain medication than others who have experienced the same painful procedures (Scherder et al. 2009). 
Effective approaches to assessment and intervention are comprehensive in nature, with a focus on domains beyond the primary presenting condition; and multi-faceted, requiring multidisciplinary input and a focus on care coordination or case management. A number of models of care targeted at people with dementia in hospital, or at hospitalised older people, were identified, although there is no evidence for the specific impact of dementia specialists within these interventions.

Specialised care units and specialist consultation teams have been associated with improved care for older people in hospital. One scoping review identified eight different specialised care units for older people that commonly included interdisciplinary specialised geriatric resources on designated units (Parke et al. 2012). None were focused on patients with dementia, although the Hospital Elder Life Program (HELP) is aimed at reducing delirium in hospitalized older adults and an evaluation found significant improvement in the degree of cognitive impairment among patients with impairment at admission (Inouye et al. 1999). Spencer and colleagues (Spencer et al. 2013) found that a specialist unit which had enhanced staffing from mental health nurses and OT's, the introduction of activities, personalised care plans, improved environment and training, and resulted in improved carer satisfaction.

Parke et al. (2012) also identified a range of specialised consultation teams for older hospitalised adults, including one led by a geriatrician trained in geriatric psychiatry and including a specialised geriatric liaison nurse. The team focused on providing psychogeriatric liaison for medical patients. A randomised controlled trial showed improvements in physical functioning, length of stay, readmissions and nursing home placements (Slaets et al. 1997). A Cochrane systematic review on comprehensive geriatric assessment (CGA) for older hospital patients concludes that CGA increases a patient's likelihood of being alive and in their own home at up to 12 months (Ellis et al. 2011), but only two of the 22 included trials evaluated CGA for patients with dementia (Cole et al. 1991, Volicer et al. 1994). 
In general hospital settings dementia care mapping (DCM), a care improvement process to enhance person-centred care for people with dementia has been shown to be feasible (He et al. 2012). There is some evidence to support its efficacy in long-term care settings however, its impact on patient outcomes in acute settings has not yet been established.

A dementia specialist nurse could:

- Lead the development and implementation of multidisciplinary programmes of care

- Provide nursing input as a member of a specialist team

\section{Developing the skills of non-specialist staff}

As noted earlier, training in dementia care is required for most staff in general hospitals - from basic awareness training through to more comprehensive training for staff delivering direct care to people with dementia. Relevant features of educational interventions described in the literature include designing an educational plan based on assessment of a team's educational needs (Iliffe et al. 2012); the use of strategies such as dementia care mapping (Brooker 2005); practice-based education and role modelling (Burgess 2003, Feldt \& Ryden 1992); and the inclusion in training programmes of content related to communication strategies, management of disturbing behaviours, focusing on resident/patient abilities, caregiver involvement, patient safety, advocacy, pain management and ethics (Andrews \& Christie 2009, Cunningham \& McWilliam 2006, Douglas-Dunbar \& Gardiner 2007, James J \& Hodnett 2009, Wells et al. 2000). However the evidence base for these features is mostly weak.

Two systematic reviews indicate that educational interventions that are strongly theoretically based, multi-faceted, of sufficient intensity and duration, and supplemented by additional supervision and sufficient management support, may deliver the best outcomes, while concluding that the evidence base is weak (Kuske et al. 2007, Spector et al. 2013). Tailored feedback on 
performance is supported by a high quality systematic review as a strategy that leads to change in professional behavior and patient outcomes (Ivers et al. 2012).

A dementia specialist nurse could:

- Lead the assessment of educational need across staff groups

- Design, deliver and evaluate classroom-based and ward-based education

- Lead the implementation of strategies such as dementia care mapping

- Role model best practice to colleagues through collaboration and participation in patient care

- Guide assessment of the effect of education and support change through audits of practice and individualized feedback

\section{DISCUSSION}

Hospitals in many health care systems are making improvements to services provided to people with dementia but this is often in the absence of a robust evidence base. This review has focused on identifying and synthesising evidence of measurable effect that could guide the development of nurse specialist roles. There is little direct evidence because this is a new role. There is however, ample evidence that gives confidence that a dementia specialist nurse working in an acute setting could improve the experience and outcomes of hospital care for people with dementia and their family carers and reduce the excess costs of care by delivering services and interventions that are themselves based on evidence. Interventions of known effectiveness that could be delivered or enhanced by specialist nurses include focal interventions such as falls prevention and wider service reconfigurations such as transitional care programmes.

To be effective and efficient, the dementia specialist nurse role will need aligning with other services, such as community services, medicine and psychiatry for older people, but with attention paid to offering a direct service to patients and families that is new and distinctive, rather than 
simply replicating, or substituting for, the work of others. The review findings indicate a wide range of potential demands on a nurse specialist and hence a risk that they are asked to do far too much to have any measurable benefit. Additionally to these direct care roles, there is potential for senior specialist nurses to support and further develop care standards across the organisation, bridging boundaries between professional groups. To succeed they would need significant expertise, seniority and authority and to be recognised as opinion leaders by senior colleagues from other disciplines (Flodgren et al. 2011). Their reduced capacity to deliver one-to-one patient care must be explicitly recognised. Strategic goals must be clear, the appropriate levers of action identified and the required structures must be in place to make success possible. The limitations of educational interventions need to be acknowledged and the efforts of specialist nurses need to be targeted so they can support behaviour change through role modelling and provision of targeted feedback on performance to others (Ivers et al. 2012).

The size of the patient population with dementia in many hospitals means that it is unlikely that one person with a dementia remit can make a measurable difference to all dementia patients, unless the role is focused on facilitating the adoption of evidence-based strategies in staff groups across the hospital. A clear balance needs to be struck between the benefits to individual patients with dementia and their carers from the direct involvement of a specialist in their care, and the need for whole organisations to shift their thinking and practice to more dementia-friendly ways. It may be that most organisations need more than one dementia specialist nurse. To deliver benefit, the case load must be such that the nurse can have a meaningful impact (Brooten et al. 2012). Based on the case loads identified by the single direct evaluation that we found (Elliot \& Adams 2011) it appears that there should be at least one whole time equivalent dementia specialist nurse for every 300 annual hospital admissions of people with dementia per year.

It will be important to be mindful of lessons learned from the implementation of other advanced practice nursing roles. Bryant-Lukosius (2004) summarised the issues. Organizations often initiate 
new roles as a solution to a specific health care issue but do not set well-defined achievable goals based on a systematic needs assessment and clear understanding of the evidence base for what is feasible and effective. Organizations fail to define new roles and how they will achieve priorities for improving health care. In the absence of clear or realistic goals, roles become shaped by the expectations of stakeholders such as managers and nurses in the role, resulting in wide variations in how roles are interpreted and used. Lack of role clarity and inconsistent expectations contribute to problems such as role conflict, role overload, and variable stakeholder acceptance. The novelty of the role for others who interface with it can lead to misinterpretation and under-use of the role (Bryant-Lukosius et al. 2004).

We identified little specific evidence regarding the personal characteristics and competencies required in a dementia specialist nurse although the evidence we reviewed does give a broad indication of generic and specific competencies. In the USA and Canada, and in some UK hospitals, masters preparation is required for clinical nurse specialist roles and where educational level is specified in the interventions we reviewed, masters-prepared nurses commonly feature. However, a recent survey suggests that a relatively small proportion of existing dementia specialist nurses are qualified to this level (Griffiths et al. 2013a, Griffiths et al. 2013b). The existing capacity of the workforce to assume these roles is unclear,

Because the evidence base presented is indirect, implementation should be accompanied by the use of routine data for local evaluation and more definitive evaluation of effectiveness through cluster randomised controlled trials or observational studies based on natural experiments, and qualitative studies that identify the barriers and facilitators to role effectiveness.

\section{CONCLUSIONS}

Dementia specialist nurses working in an acute setting could deliver benefit for people with dementia and their family carers, but such roles need to be careful designed. The evidence indicates that there is a need to move beyond broad role descriptors to the design of a specific 'job' delivering 
effective interventions and programmes of care with a defined 'caseload'. The specific competencies and skills required should be relevant to the services to be delivered. It is unlikely that one specialist nurse with a dementia remit can make a measurable difference to all dementia patients in a large hospital. To deliver benefit the case load must be such that the nurse can have a meaningful impact. Strategic leadership elements of the role require the specialist nurse to have the positioning, expertise and authority to enact these successfully.

\section{RELEVANCE TO CLINICAL PRACTICE}

This paper provides clear guidance for the development and implementation of dementia specialist nurse roles in acute hospital settings. The existing evidence indicates that dementia specialist nurses working in an acute setting could deliver benefit for people with dementia in hospital and their family carers. Such roles should be carefully designed and targeted at activities for which the evidence base is strongest. 


\section{References}

Alzheimer's Disease International (2013) The global impact of dementia 2013-2050, London.

Alzheimers Society (2009) Counting the cost: Caring for people with dementia on hospital wards. Alzheimer's Society, London.

Andrews J \& Christie J (2009): Emergency care for people with dementia. Emergency Nurse 17, 12, 14.

Arksey H \& O'Malley L (2005): Scoping studies: towards a methodological framework. International Journal of Social Research Methodology 8, 19 - 32.

Benedict L, Robinson K \& Holder C (2006): Clinical nurse specialist practice within the Acute Care for Elders interdisciplinary team model. Clin Nurse Spec 20, 248-251.

Bradway C, Trotta R, Bixby MB, McPartland E, Wollman MC, Kapustka H, McCauley K \& Naylor MD (2012): A qualitative analysis of an advanced practice nurse-directed transitional care model intervention. Gerontologist 52, 394-407.

Bridges J, Flatley M \& Meyer J (2010): Older people's and relatives' experiences in acute care settings: systematic review and synthesis of qualitative studies. International Journal of Nursing Studies 47, 89-107.

Brooker D (2005): Dementia care mapping: a review of the research literature. Gerontologist 45 Spec No 1, 11-18.

Brooten D, Youngblut JM, Deosires W, Singhala K \& Guido-Sanz F (2012): Global considerations in measuring effectiveness of advanced practice nurses. International Journal of Nursing Studies 49, 906-912.

Bryant-Lukosius D, DiCenso A, Browne G \& Pinelli J (2004): Advanced practice nursing roles: development, implementation and evaluation. Journal of Advanced Nursing 48, 519-529.

Brymer C, Cavanagh P, Denomy E, Wells K \& Cook C (2001): The effect of a geriatric education program on emergency nurses. Journal of Emergency Nursing 27, 27-32.

Burgess L, Page, S. (2003): Educating nursing staff involved in the provision of dementia care. Nursing Times 99, 34-37.

Butler M, Collins R, Drennan J, Halligan P, O'Mathúna DP, Schultz TJ, Sheridan A \& Vilis E (2011): Hospital nurse staffing models and patient and staff-related outcomes. Cochrane Database Syst Rev 7.

Butler R \& Radhakrishnan R (2011) Dementia. BMJ Publishing Group, http://www.clinicalevidence.co.uk/x/pdf/clinical-evidence/en-gb/systematicreview/1001.pdf (accessed 16/05/2014).

Cameron ID, Gillespie LD, Robertson MC, Murray GR, Hill KD, Cumming RG \& Kerse N (2012): Interventions for preventing falls in older people in care facilities and hospitals. Cochrane Database Syst Rev 12.

CHKS (2012) An economic analysis of the excess costs for acute care for patients with dementia. CHKS, http://www.chks.co.uk/userfiles/files/Dementia an economic analysis.pdf (accessed 04.06.2014).

Clevenger CK, Chu TA, Yang Z \& Hepburn KW (2012): Clinical care of persons with dementia in the emergency department: a review of the literature and agenda for research. Journal of the American Geriatrics Society 60, 1742-1748.

Cole MG, Fenton FR, Engelsmann F \& Mansouri I (1991): Effectiveness of geriatric psychiatry consultation in an acute care hospital: A randomized clinical trial. J Am Geriatr Soc 39, 11831188.

Crisp H (2011) Spotlight on Dementia Care. Health Foundation, London.

Crotty M, Unroe K, Cameron Ian D, Miller M, Ramirez G \& Couzner L (2010) Rehabilitation interventions for improving physical and psychosocial functioning after hip fracture in older people. In Cochrane Database of Systematic Reviews. John Wiley \& Sons, Ltd, Chichester, UK. 
Cunningham C \& McWilliam K (2006): Caring for people with dementia in A\&E. Emerg Nurse 14, 1216.

Davis K, Drey N \& Gould D (2009): What are scoping studies? A review of the nursing literature. International Journal of Nursing Studies 46, 1386-1400.

Dewing J \& Traynor V (2005): Admiral nursing competency project: practice development and action research. J Clin Nurs 14, 695-703.

Douglas-Dunbar M \& Gardiner P (2007): Support for carers of people with dementia during hospital admission. Nursing Older People 19, 27-30.

Elliot R \& Adams J (2011): The creation of a Dementia Nurse Specialist role in an acute general hospital. Journal of Psychiatric and Mental Health Nursing 18, 648-652.

Ellis G, Whitehead Martin A, O'Neill D, Langhorne P \& Robinson D (2011) Comprehensive geriatric assessment for older adults admitted to hospital. In Cochrane Database of Systematic Reviews. John Wiley \& Sons, Ltd.

Feldt KS \& Ryden MB (1992): Aggressive behavior. Educating nursing assistants. J Gerontol Nurs 18, 3-12.

Flodgren G, Parmelli E, Doumit G, Gattellari M, O'Brien MA, Grimshaw J \& Eccles MP (2011): Local opinion leaders: effects on professional practice and health care outcomes. Cochrane Database Syst Rev 8.

Gillespie Lesley D, Robertson MC, Gillespie William J, Sherrington C, Gates S, Clemson Lindy M \& Lamb Sarah E (2012) Interventions for preventing falls in older people living in the community. In Cochrane Database of Systematic Reviews. John Wiley \& Sons, Ltd.

Goldberg SE, Whittamore KH, Harwood RH, Bradshaw LE, Gladman JR \& Jones RG (2012): The prevalence of mental health problems among older adults admitted as an emergency to a general hospital. Age and Ageing 41, 80-86.

Greenhalgh T (2014) How to read a paper: the basics of evidence-based medicine. John Wiley \& Sons, Chichester.

Griffiths P, Bridges J \& Sheldon H (2013a) Scoping the role of the dementia nurse specialist in acute care. University of Southampton, http://eprints.soton.ac.uk/id/eprint/349714 (accessed 04.06.2014).

Griffiths P, Jones S, Maben J \& Murrells T (2008) State of the art metrics for nursing: a rapid appraisal. King's College London, London.

Griffiths P, Sheldon H, Bridges J, Bartlett R \& Hunt K (2013b) Scoping the role of the dementia nurse specialist in acute care: technical appendices. University of Southampton, http://eprints.soton.ac.uk/349714/ (accessed 04.06.2014).

Griffiths P, Simon M, Richardson A \& Corner J (2013c): Is a larger specialist nurse workforce in cancer care associated with better patient experience? Cross-sectional study. Journal of Health Services Research and Policy 18, 39-46.

Haines T, Hill A, Hill KD, McPhail S, Oliver D, Brauer S, Hoffmann T \& Beer C (2011): Patient education to prevent falls among older hospital inpatients: A randomized controlled trial. Archives of Internal Medicine 171, 516-524.

Haines TP, Bennell KL, Osborne RH \& Hill KD (2004): Effectiveness of targeted falls prevention programme in subacute hospital setting: randomised controlled trial. $B M J \mathbf{3 2 8}, 676$.

Handoll HH, Cameron ID, Mak JC \& Finnegan TP (2009): Multidisciplinary rehabilitation for older people with hip fractures. Cochrane Database Syst Rev, CD007125.

Handoll HHG, Sherrington C \& J.C.S. M (2011) Interventions for improving mobility after hip fracture surgery in adults. In Cochrane Database of Systematic Reviews. John Wiley \& Sons, Ltd.

Hare M, Wynaden D, McGowan S \& Speed G (2008): Assessing cognition in elderly patients presenting to the emergency department. International Emergency Nursing 16, 73-79.

He J, Dunton N \& Staggs V (2012): Unit-level time trends in inpatient fall rates of US hospitals. Medical Care 50, 801-807. 
Iliffe S, Koch T, Jain P, Lefford F, Wong G, Warner A \& Wilcock J (2012): Developing an educational intervention on dementia diagnosis and management in primary care for the EVIDEM-ED trial. Trials 13, 142.

Inouye SK, Bogardus ST, Charpentier PA, Leo-Summers L, Acampora D, Holoford TR \& Cooney LM (1999): A multicomponent intervention to prevent delirium in hospitalized older patients. New England Journal of Medicine 340, 669-676.

Inouye SK, Wagner DR, Acampora D, Horwitz RI, Cooney LM, Jr \& Tinetii ME (1993): A controlled trial of a nursing-centered intervention in hospitalized elderly medical patients: the Yale Geriatric Care Program. Journal of the American Geriatrics Society 41, 1353-1360.

Ivers N, Jamtvedt G, Flottorp S, Young Jane M, Odgaard-Jensen J, French Simon D, O'Brien Mary A, Johansen M, Grimshaw J \& Oxman Andrew D (2012) Audit and feedback: effects on professional practice and healthcare outcomes. In Cochrane Database of Systematic Reviews. John Wiley \& Sons, Ltd.

James J \& Hodnett C (2009): Taking the anxiety out of dementia. Emerg Nurs 200 16:10-13.

Kazui H, Hashimoto M, Nakano Y, Matsumoto K, Yamamura S, Nagaoka K, Mori E, Endo H, Tokunaga $\mathrm{H}$, Ikejiri Y \& Takeda M (2004): Effectiveness of a clinical pathway for the diagnosis and treatment of dementia and for the education of families. International Journal of Geriatric Psychiatry 19, 892-897.

Krichbaum K (2007): GAPN postacute care coordination improves hip fracture outcomes. West J Nurs Res 29, 523-544.

Kuske B, Hanns S, Luck T, Angermeyer MC, Behrens J \& Riedel-Heller SG (2007): Nursing home staff training in dementia care: a systematic review of evaluated programs. Int Psychogeriatr 19, 818-841.

Leary A, Crouch H, Lezard A, Rawcliffe C, Boden L \& Richardson A (2008): Dimensions of clinical nurse specialist work in the UK. Nursing Standard 23, 40-44.

Maben J, Morrow E, Ball J, Robert G \& Griffiths P (2012) High Quality Care Metrics for Nursing. National Nursing Research Unit, King's College London, London.

Mason M-C (2011): Environmental health. Nursing Standard 26, 23-25.

McCulla MM, Coats M, Van Fleet N, Duchek J, Grant E \& Morris JC (1989): Reliability of clinical nurse specialists in the staging of dementia. Archives of Neurology 46, 1210-1211.

Mukadam N \& Sampson EL (2011): A systematic review of the prevalence, associations and outcomes of dementia in older general hospital inpatients. Int Psychogeriatr 23, 344-355.

Naylor MD, Aiken LH, Kurtzman ET, Olds DM \& Hirschman KB (2011): The importance of transitional care in achieving health reform. Health Affairs 30, 746-754.

Naylor MD, Hirschman KB, Bowles KH, Bixby MB, Konick-McMahan J \& Stephens C (2007): Care coordination for cognitively impaired older adults and their caregivers. Home Health Care Services Quarterly 26, 57-78.

Naylor MD, Stephens C, Bowles KH \& Bixby MB (2005): Cognitively impaired older adults: from hospital to home. Am J Nurs 105, 52-61; quiz 61-52.

Newhouse R, Stanik-Hutt J, White K, Johantgen M, Bass E, Zangaro G, Wilson R, Fountain L, Steinwachs D \& Heindel L (2011): Advanced practice nurse outcomes 1990-2008: a systematic review. Nursing Economics 29, 230.

Oliver D, Connelly JB, Victor CR, Shaw FE, Whitehead A, Genc Y, Vanoli A, Martin FC \& Gosney MA (2007): Strategies to prevent falls and fractures in hospitals and care homes and effect of cognitive impairment: systematic review and meta-analyses. British Medical Journal 334, 82.

Page S, Hope K, Bee P \& Burns A (2008): Nurses making a diagnosis of dementia--a potential change in practice? International Journal of Geriatric Psychiatry 23, 27-33.

Parke B, Hunter KF, Bostrom AM, Chambers T \& Manraj C (2012): Identifying modifiable factors to improve quality for older adults in hospital: a scoping review. International Journal of Older People Nursing 9, 8-24. 
Royal College of Nursing (2010) Specialist Nurses: Changing lives saving money. Royal College of Nursing, London.

Royal College of Psychiatrists (2011) Report of the National Audit of Dementia Care in General Hospitals 2011. HQIP, London.

Royal College of Psychiatrists (2013) National Audit of Dementia Care in General Hospitals 2012-13: second round audit report and update. (Young J, Hood C, Gandesha A \& Souza R eds.). HQIP, London.

Rubin FH, Williams JT, Lescisin DA, Mook WJ, Hassan S \& Inouye SK (2006): Replicating the Hospital Elder Life Program in a community hospital and demonstrating effectiveness using quality improvement methodology. Journal of the American Geriatrics Society 54, 969-974.

Ryden MB, Snyder M, Gross CR, Savik K, Pearson V, Krichbaum K \& Mueller C (2000): Value-added outcomes: the use of advanced practice nurses in long-term care facilities. The Gerontologist 40, 654-662.

Sampson EL, Leurent B, Blanchard MR, Jones L \& King M (2012): Survival of people with dementia after unplanned acute hospital admission: a prospective cohort study. International Journal of Geriatric Psychiatry 28, 1015-1022.

Scherder E, Herr K, Pickering G, Gibson S, Benedetti F \& Lautenbacher S (2009): Pain in dementia. Pain 145, 276-278.

Shepperd S, McClaran J, Phillips Christopher O, Lannin Natasha A, Clemson Lindy M, McCluskey A, Cameron lan D \& Barras Sarah L (2010) Discharge planning from hospital to home. In Cochrane Database of Systematic Reviews. John Wiley \& Sons, Ltd.

Skills for Health (2010) Working to support the implementation of the National Dementia Strategy Project: scoping study report. Department of Health, http://dementia.dh.gov.uk/ensuringan-informed-and-effective-workforce-for-people-with-dementia/ (accessed 07.11.2012).

Slaets J, Kauffmann R, Duivenvoorden H, Pelemans W \& Schudel WJ (1997): A randomized trial of geriatric liaison intervention in elderly medical inpatients. Psychosomatic medicine 59, 585591.

Spector A, Orrell M \& Goyder J (2013): A systematic review of staff training interventions to reduce the behavioural and psychological symptoms of dementia. Ageing Research Reviews 12, 354364.

Spencer K, Foster P, Whittamore KH, Goldberg SE \& Harwood RH (2013): Delivering dementia care differently-evaluating the differences and similarities between a specialist medical and mental health unit and standard acute care wards: a qualitative study of family carers' perceptions of quality of care. BMJ open 3, e004198.

Steele JS (2010): Current evidence regarding models of acute care for hospitalized geriatric patients. Geriatric Nursing 31, 331-347.

Thomas C, Kreisel SH, Oster P, Driessen M, Arolt V \& Inouye SK (2012): Diagnosing delirium in older hospitalized adults with dementia: adapting the Confusion Assessment Method to International Classification of Diseases, Tenth Revision, Diagnostic Criteria. Journal of the American Geriatrics Society 60, 1471-1477.

Thompson R \& Heath H (2011) Commitment to the care of people with dementia in hospital settings. RCN, London.

Tueth MJ (1995): Dementia: Diagnosis and emergency behavioral complications. The Journal of Emergency Medicine 13, 519-525.

Udell J, E., Drahota A, Dean Taraneh P, Sander R \& Mackenzie H (2011) Interventions for preventing falls in older people: an overview of Cochrane Reviews. In Cochrane Database of Systematic Reviews. John Wiley \& Sons, Ltd.

van Gaal BGI, Schoonhoven L, Mintjes JAJ, Borm GF, Hulscher MEJL, Defloor T, Habets H, Voss A, Vloet LCM, Koopmans RTCM \& van Achterberg T (2011): Fewer adverse events as a result of the SAFE or SORRY? programme in hospitals and nursing homes. Part I: Primary outcome of a cluster randomised trial. International Journal of Nursing Studies 48, 1040-1048. 
Volicer L, Collard A, Hurley A, Bishop C \& et al. (1994): Impact of special care unit for patients with advanced Alzheimer's disease on patients' discomfort and costs. Journal of the American Geriatrics Society 42, 597-603.

Wells DL, Dawson P, Sidani S, Craig D \& Pringle D (2000): Effects of an abilities-focused program of morning care on residents who have dementia and on caregivers. J Am Geriatr Soc 48, 442449.

Wimo A \& Prince MJ (2010) World Alzheimer Report 2010: the global economic impact of dementia. Alzheimer's Disease International.

Zimmermann P \& Ortigara A (1998): Caring for the patient with Alzheimer's Disease. Emergency nurse: the journal of the RCN Accident and Emergency Nursing Association 6, 11.

Figure 1: Simple hierarchy of evidence (from Greenhalgh 2014)

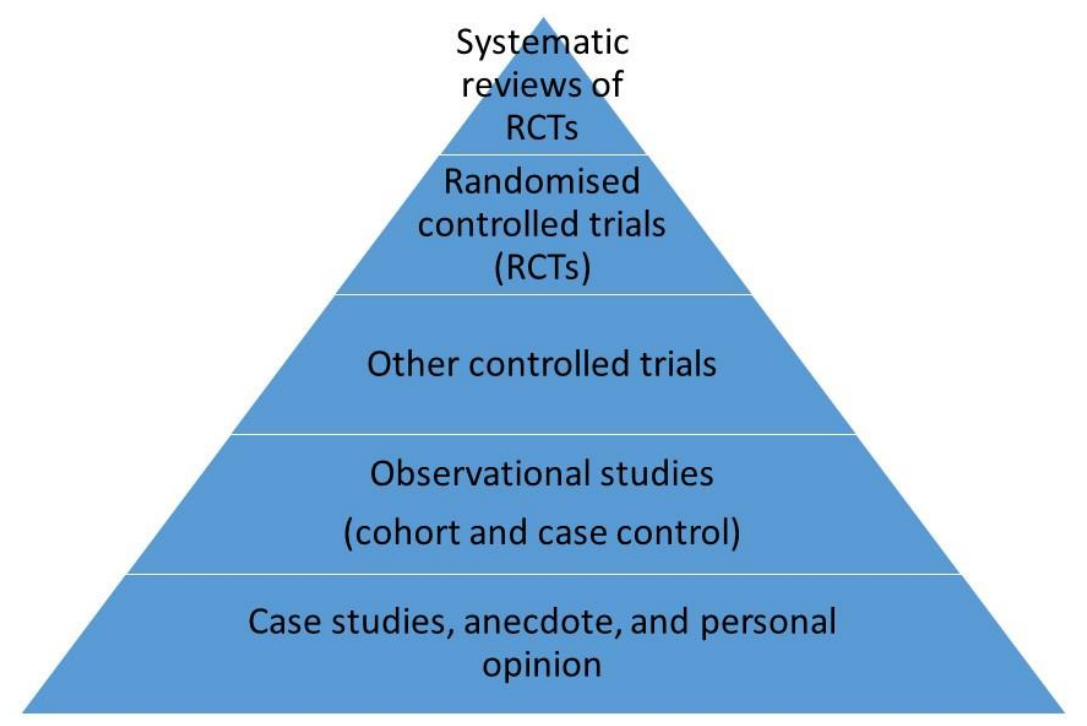

Table 1: Summarised scoping review outcomes

\begin{tabular}{|l|l|}
\hline & $\begin{array}{l}\text { Number of papers included in } \\
\text { final review }\end{array}$ \\
\hline Falls & 6 \\
\hline Length of stay & 5 \\
\hline Readmissions & 11 \\
\hline Other adverse events & 9 \\
\hline Screening and diagnosis & 12 \\
\hline Models of care & 16 \\
\hline Developing staff skills & 12 \\
\hline
\end{tabular}

